\title{
Factors driving patterns and trends in strandings of small cetaceans
}

\author{
Camilo Saavedra $^{1 *}$, Graham J. Pierce ${ }^{2,3}$, Jesús Gago ${ }^{1}$, Dunja Jusufovski ${ }^{4}$, Águeda Cabrero ${ }^{1}$, Santiago
} Cerviño ${ }^{1}$, Alfredo López ${ }^{5}$, Jose A. Martínez-Cedeira ${ }^{5}$, M. Begoña Santos ${ }^{1}$.

${ }^{1}$ Instituto Español de Oceanografía, Centro Oceanográfico de Vigo, P.O. Box 1552, 36200 Vigo, Spain. ${ }^{2}$ CSIC Consejo Superior de Investigaciones Científicas, Eduardo Cabello, 6, 36208 Vigo, Pontevedra, Spain ${ }^{3}$ CESAM \& Departamento de Biologia, Universidade de Aveiro, 3810-193 Aveiro, Portugal.

${ }^{4}$ Department of Environmental Sciences, University of Helsinki, Helsinki, Finland.

${ }^{5}$ Coordinadora para o Estudio dos Mamíferos Mariños (CEMMA), 156-36380, Gondomar, Spain.

* Corresponding author: camilo.saavedra.penas@gmail.com +34 986492111 orcid.org/0000-0003-1032-647X

\section{Abstract}

The incidence of cetacean strandings is expected to depend on a combination of factors, including the distribution and abundance of the cetaceans, their prey, and causes of mortality (e.g., natural, fishery bycatch), as well as currents and winds which affect whether carcases reach the shore. We investigated spatiotemporal patterns and trends in the numbers of strandings of three species of small cetacean in Galicia (NW Spain) and their relationships with meteorological, oceanographic, prey abundance and fishing-related variables, aiming to disentangle the relationship that may exist between these factors, cetacean abundance and mortality off the coast. Strandings of 1166 common dolphins (Delphinus delphis), 118 bottlenose dolphins (Tursiops truncatus) and 90 harbour porpoises (Phocoena phocoena) during 2000 to 2013 were analysed. Generalised Additive and Generalised Additive Mixed model results showed that the variables which best explained the pattern of strandings of the three cetacean species were those related with local ocean meteorology (strength and direction of the North-South component of the winds and the number of days with South West winds) and the winter North Atlantic Oscillation Index. There were no significant relationships with indices of fishing effort or landings. Only bottlenose dolphin showed possible fluctuations in local abundance over the study period. There was no evidence of long-term trends in number of strandings in any of the species and their abundances were therefore considered to have been relatively stable during the study period.

\section{Keywords}

Strandings, Oceanography, Fishing effort, Common dolphin, Bottlenose dolphin, Harbour porpoise, NE Atlantic. 
33 The authors wish to thank all the volunteers and members of CEMMA who attended the strandings, as well as 34 the researchers who contributed, through different studies and projects, to the improvement of the cetacean 35 database. The standing network was partially funded by the "Dirección Xeral de Conservación da Natureza da 36 Xunta de Galicia" in Spain and by the "Fundação para a Ciência e Tecnologia" in Portugal. The research 37 leading to these results has received funding from the European Union's Seventh Framework Programme 38 (FP7/2007-2013) under grant agreement $n^{\circ} 613571$ - MareFrame. The main author (C.S.) received a pre39 doctoral grant from the Spanish Institute of Oceanography (BOE-A-2011-2541). We thank the editor and two anonymous reviewers for their valuable comments on the manuscript. 


\section{Introduction}

Strandings can provide valuable information on the presence and relative abundance of cetaceans in an area (e.g., López et al. 2002; Siebert et al. 2006; Leeney et al. 2008; Truchon et al. 2013), also allowing collection of samples to characterise life history, contaminant burdens, diet and feeding ecology, population genetics and other information for individuals and populations (López 2003; Pierce et al. 2008; Fontaine et al. 2010; Fernández et al. 2011; Murphy et al. 2013; Méndez-Fernandez et al. 2014; Santos et al. 2014). Nevertheless, the relationship between stranding patterns and population dynamics is often unclear. The number of deaths depends, obviously, on the abundance of a population, which can vary over seasons and/or years, and on its mortality rate (i.e., its natural and anthropogenic mortality). In addition, several factors influence the number of dead cetaceans found stranded, including the spatial distribution of different categories of mortality (e.g., fishery bycatch) and the likelihood that a carcase will reach the shore (which depends on factors such as proximity, buoyancy of the carcase and prevailing currents; e.g., Peltier et al. 2012). Therefore, observed trends in strandings do not necessarily have a direct relationship with population abundance. However, the monitoring of marine mammals through the collection of at-sea data remains expensive and sometimes low cost solutions are needed in order to help meet management objectives (Elzinga et al. 2001). As Caughlan \& Oakley stated (2001), the efficiency of a monitoring plan is based on three performance measures: ecological relevance, cost-effectiveness and statistical credibility. Detecting trends in the abundance of cetaceans inhabiting a given region has high ecological relevance, in addition to being especially important for population management, for example in the context of the EU Habitats Directive (Council Directive 92/43/EEC) and EU Marine Strategy Framework Directive (MSFD; Directive 2008/56/EC). On the other hand, the relatively low cost of data obtained from strandings is potentially advantageous. Thus, there is a need to improve the understanding of the underlying mechanisms that affect strandings and that may be masking their direct relationship with cetacean abundance.

Following these considerations, our work aims to identify the main external factors that affect variation in the number of cetacean strandings and thus provide insights into whether changes in the cetacean abundance or distribution can be inferred. A more comprehensive knowledge of the dynamics of the stranding process might help us to interpret patterns in terms of the abundance and mortality of populations, to identify areas or seasons with a high probability of interactions between fisheries and cetaceans and, ultimately, to assess the progress of marine mammal populations towards "Good Environmental Status", as the MSFD requires. The present work thus aims to contribute to the understanding of the dynamics of cetacean strandings in the study region.

This study focuses on the three main species of small cetaceans in Galicia, NW Spain, according to López (2003): common dolphin (Delphinus delphis), bottlenose dolphin (Tursiops truncatus) and harbour 
porpoise (Phocoena phocoena). The number of strandings of these species in the area is thought to be very high because of its geographical characteristics (i.e., presence of many beaches and inlets), the high cetacean biodiversity and abundance, and high fishery bycatch levels (López et al. 2002, 2003). In addition, due to the long-standing existence of a strandings monitoring network, long time-series of data are available (see López et al., 2002).

Dedicated surveys have estimated absolute abundances of cetaceans in Iberian shelf (SCANS-II 2006) and oceanic waters (CODA Final Report 2009). Various non-random boat-based surveys (e.g., opportunistic use of fishing vessels), systematic land-based coastal sightings surveys and interviews surveys of fishermen have provided additional information on distribution and local relative abundance (e.g., Pierce et al. 2010; Spyrakos et al. 2011; Goetz et al. 2014a). It remains the case that very little is known about seasonal and interannual variation in cetacean abundance in the area.

Absolute abundance of cetaceans cannot be estimated directly from strandings if (as is usually the case) we do not know the mortality rate, the proportion of dead dolphins that reach the coast and the proportion of strandings found by strandings networks. However, when we talk about temporal trends, absolute abundance becomes less important and we therefore focus on strandings as a potential index of relative abundance. The main objective of this work was to infer trends in the relative abundance of the selected species from the time series of strandings recorded in the coastline of our study area. To address this objective, this study was divided into two successive steps.

The first step was to identify the main factors that might be masking the relationship between cetacean strandings and their population abundance. Several meteorological (e.g., wind strength and direction) and climatic (e.g., North Atlantic Oscillation, NAO; East Atlantic pattern, EA) variables were tested to identify which ones have more influence on the number of strandings. The most common cause of mortality for cetaceans detected stranded in the area appears to be the interaction with fishing gears, since several studies have reported high levels of bycatch in Galician waters (e.g., López et al. 2003; Fernández-Contreras et al. 2010; Goetz et al. 2014b), where a fleet of more than 4000 fishing boats is licensed in Galicia to operate within the EEZ (Xunta de Galicia 2016). Quantifying the number of cetaceans that die from diseases implies a significant level of monitoring by highly specialized personnel and an adequate proportion of fresh carcasses. However, mortality due to fishing is more easily diagnosed in carcases and can in principle be related with the effort of certain fleet segments since bycatch mortality is generally considered to be effort- and metierdependent (Northridge 1984, 1991). Therefore, some measures of fishing effort were used as potential proxies of bycatch rates. On the other hand, it is known that the seasonal abundance and proximity of cetaceans to the coast is influenced by the distribution and abundance of prey (e.g., Friedlaender et al. 2006). All fish landings and landings of the main prey of the studied cetaceans were also included in this study as putative proxies of 
the relative abundance of cetacean prey.

These are the main factors identified that might influence the probability of cetacean strandings in the area of study (in addition to the abundance of these cetacean species in the surrounding waters). However, the proportion of cetaceans stranded can be also strongly influenced by the distance to the coast and carcass buoyancy, and by the amount of effort devoted to finding them, the accessibility of the coast and its proximity to human population centres (Evans et al. 2005; Peltier et al. 2012). In this study, factors such as the distance from the coast at which death took place and carcass buoyancy were not considered due to lack of data. However, it was considered that these factors might not have a strong impact when working with relative abundances and this assumption is discussed. Regarding the amount of effort devoted by the stranding network, it should not affect the relative number of cetaceans found because we have restricted the analysis to a subset of the time series during which monitoring effort was relatively constant.

Having investigated the main factors that affect the probability of stranding, a second step was to determine the temporal variability in the estimated relative abundance of the selected species. Two approaches were used and their results compared: firstly, the numbers of cetacean strandings were modelled as a function of year and month, thus representing between-year and within-year variability, but not taking into account the factors that may mask their relationship with population abundance. The year effect was fitted in two ways, as an unconstrained smoother, and as a linear effect. Secondly, the variables significantly related with the variations in strandings identified in the previous step were included in these models, aiming to disentangle the relative contribution of these factors in determining the actual trends in population abundance. That way we can interpret the partial effect of year not as simply the variation in the observed numbers of strandings but as a proxy for the abundance of cetaceans off the coast, reflecting both variations in the total population abundance and possible migratory movements.

\section{Materials and methods}

\subsection{Strandings data}

The non-governmental organisation "Coordinadora para o Estudo dos Mamíferos Mariños" (CEMMA) runs the Galician strandings network and has been collecting data from stranded marine mammals since 1990. Marine mammals stranded, bycaught or found floating are routinely reported to a 24-h phone line by members of the public, fishermen or local authorities (see López et al. 2002). Although CEMMA has operated since 1990, during the first years the capacity to attend stranded animals was limited. In 1998 a mobile unit was established and in subsequent years it was fully operational, facilitating access to the entire coastline. 
139 Since then, the stranding network has attended all reported strandings. As a precautionary measure with the 140 purpose of keeping the searching effort as constant as possible, we analysed data only from 2000 to 2013.

141 The most frequently stranded cetacean species in the region, common dolphin (DDE), bottlenose 142 dolphin (TTR) and harbour porpoise (PPH) were analysed. For each carcass, the state of preservation, 143 biological data, biological samples and photographs were routinely taken. Moreover, post-mortem 144 examinations were carried out to determine possible evidence of bycatch, following protocols described by 145 Kuiken (1994). Although the stranding network also recorded cetaceans found floating close to the coast and 146 bycaught dolphins handed over by fishermen, for consistency, only those found stranded on the coastline were 147 used in the present analysis. In addition, only stranded animals with a condition state from 1 to 4 , following 148 the Kuiken (1994) scale, were used, to avoid including remains (such as bones and highly decomposed 149 carcasses) for which it was difficult to determine stranding date. The study area and the temporal and spatial 150 distribution of the strandings used can be seen in Fig. 1. 

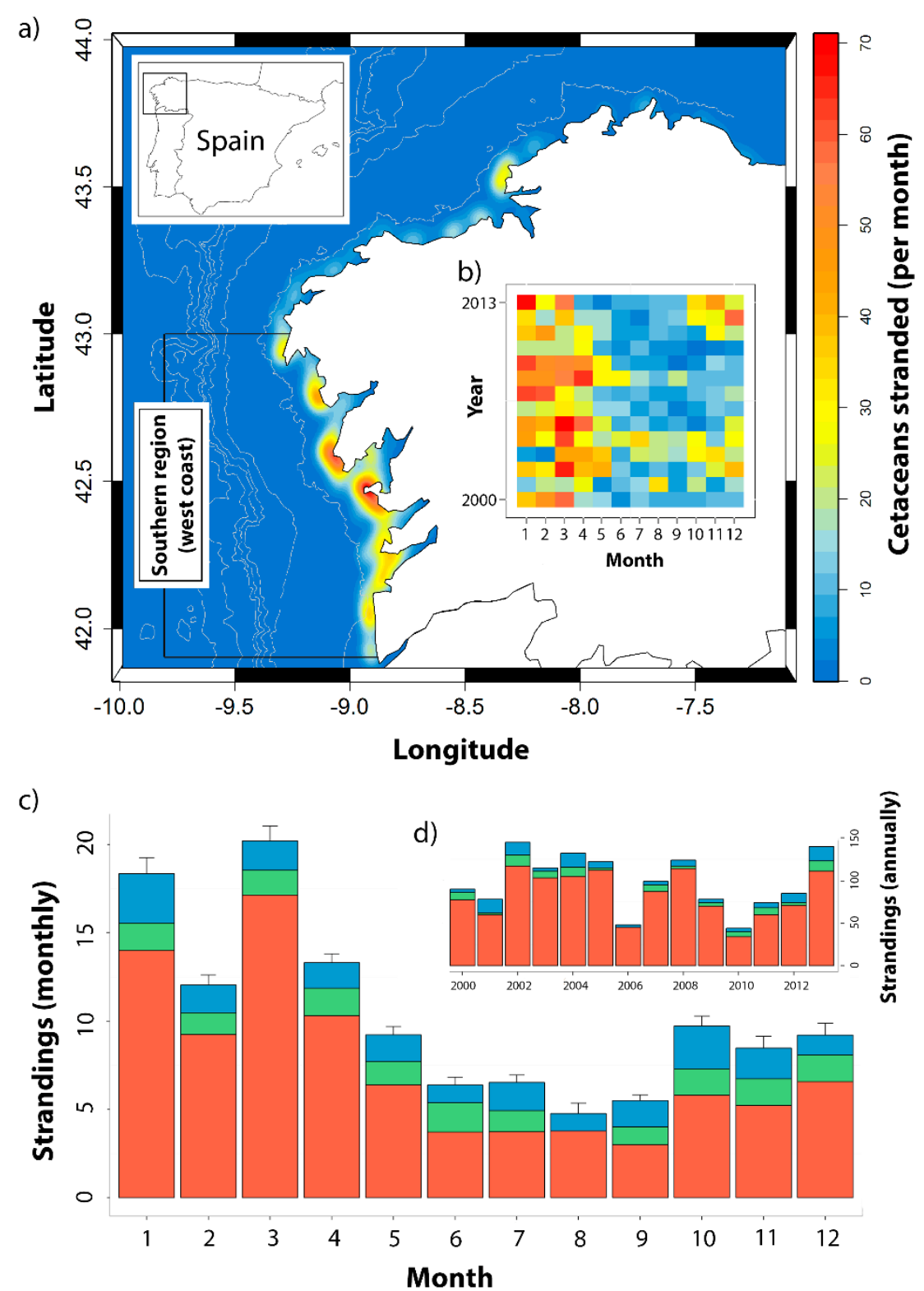

153 Fig.1 a) Map of the study area (Galicia), in the northwest of Spain (see detail in the box at the top left corner). The number of strandings of the three cetacean species (common dolphin, bottlenose dolphin and harbour porpoise) pooled together

155 was plotted using a kernel function. b) Heater plot representing the number of strandings pooled by year and month. c) 156 Monthly mean number of strandings for the three cetacean species: common dolphin (red), bottlenose dolphin (blue) and harbour porpoise (green). Standard error of the mean is represented. d) Annual number of cetaceans found stranded in the area of study for the three cetacean species (same colours for cetacean species as in figure c)

\subsection{Oceanographic characteristics of the study area}

Galicia has a coastline of about 1,200 km and a relatively narrow (i.e., $~ 10 \mathrm{~km}$ ) continental shelf 
(López-Jamar et al. 1992). In this region the along-shore winds interact with the coastal topography to generate upwelling-downwelling dynamics on the continental shelf (González-Nuevo et al. 2014). The NW Iberian Peninsula $\left(42-44^{\circ} \mathrm{N}\right)$ represents the northern extreme of the NW Africa upwelling system (Wooster et al. 1976). The upwelling season usually occurs from March to September, when the weakening of the Iceland Low and strengthening and northward displacement of the Azores High promote northerly winds. During the rest of the year, due to intensification of the Iceland Low, the winds are predominantly from the south and the south-west; favouring the predominance of downwelling conditions (see wind patterns in Fig. 2). Thus, along the western coastline predominant winds in winter favour the movement of cetacean carcases towards the coast. In contrast, it is expected that northerly winds and the upwelling tend to move carcases away from the coast during the summer months. Due to its different orientation, the influence of these phenomena on strandings is expected to be weaker along the northern coast.

Meteorological phenomena and oceanographic dynamics of the Galician coast change throughout the year and some indices can give quantitative information of these conditions. In order to study their relationship with the stranding patterns, those indices and measures that were considered likely to be most influential were selected (see Table 1 for detailed descriptions of variables and sources). The climatic and oceanographic variables selected were: The North Atlantic Oscillation (NAO), the Winter North Atlantic Oscillation $\left(\mathrm{NAO}_{\text {WIN }}\right.$ ), the East Atlantic pattern (EA), the Scandinavian pattern (SCA) and the Upwelling Index (UI). The climate variables chosen (i.e., NAO, EA, SCA) were those most commonly used to capture large-scale ocean climate variability in the eastern north Atlantic (see Table 1 for description). The UI $\left(\mathrm{m}^{3} \mathrm{~s}^{-1} \mathrm{~km}^{-1}\right)$ calculated at the position $43^{\circ} \mathrm{N} 11^{\circ} \mathrm{W}$ was chosen in order to capture atmospheric regional variability (González-Nuevo et al. 2014). In addition, westerly and northerly wind components $\left(\mathrm{m} \mathrm{s}^{-1}\right)$ obtained from the Fleet Numerical Meteorology and Oceanography Center (FNMOC) model of the National Oceanic and Atmospheric Administration (NOAA) and equivalent horizontal (U) and vertical (V) components of local winds measured at the Silleiro buoy $\left(42.12^{\circ} \mathrm{N} 9.43^{\circ} \mathrm{W}\right.$ ) by the Spanish Institute of Oceanography (IEO for its acronym in Spanish), were included as potential explanatory variables, ( $\mathrm{U}_{\mathrm{FMNOC}}, \mathrm{V}_{\mathrm{FMNOC}}, \mathrm{U}_{\mathrm{BUOY}}, \mathrm{V}_{\mathrm{BUOY}}$ respectively). Since wind direction during each month is highly variable, the mean direction is not always informative, so we also used the number of days per month, from both sources, on which there were strong favourable southwest winds ( $\mathrm{SW}_{\mathrm{FMNOC}}$ and $\mathrm{SW}_{\mathrm{BUOY}}$ ). Only days with winds stronger than $10 \mathrm{~m} \mathrm{~s}^{-1}$ were counted as positive values for $\mathrm{SW}_{\mathrm{FMNOC}}$ and winds stronger than $5 \mathrm{~m} \mathrm{~s}^{-1}$ for $\mathrm{SW}_{\mathrm{BUOY}}$ (where wind strength recorded is in general weaker). Some of the variables selected have daily or even higher resolution available but, for the sake of data standardization, the final resolution used in the analysis was monthly, obtained by calculating an arithmetic mean when this was required. The only exception was the $\mathrm{NAO}_{\mathrm{WIN}}$ for which the resolution is annual (since it is a mean of the NAO during the winter months, December to March) and thus the same value was used for all months of each year. 


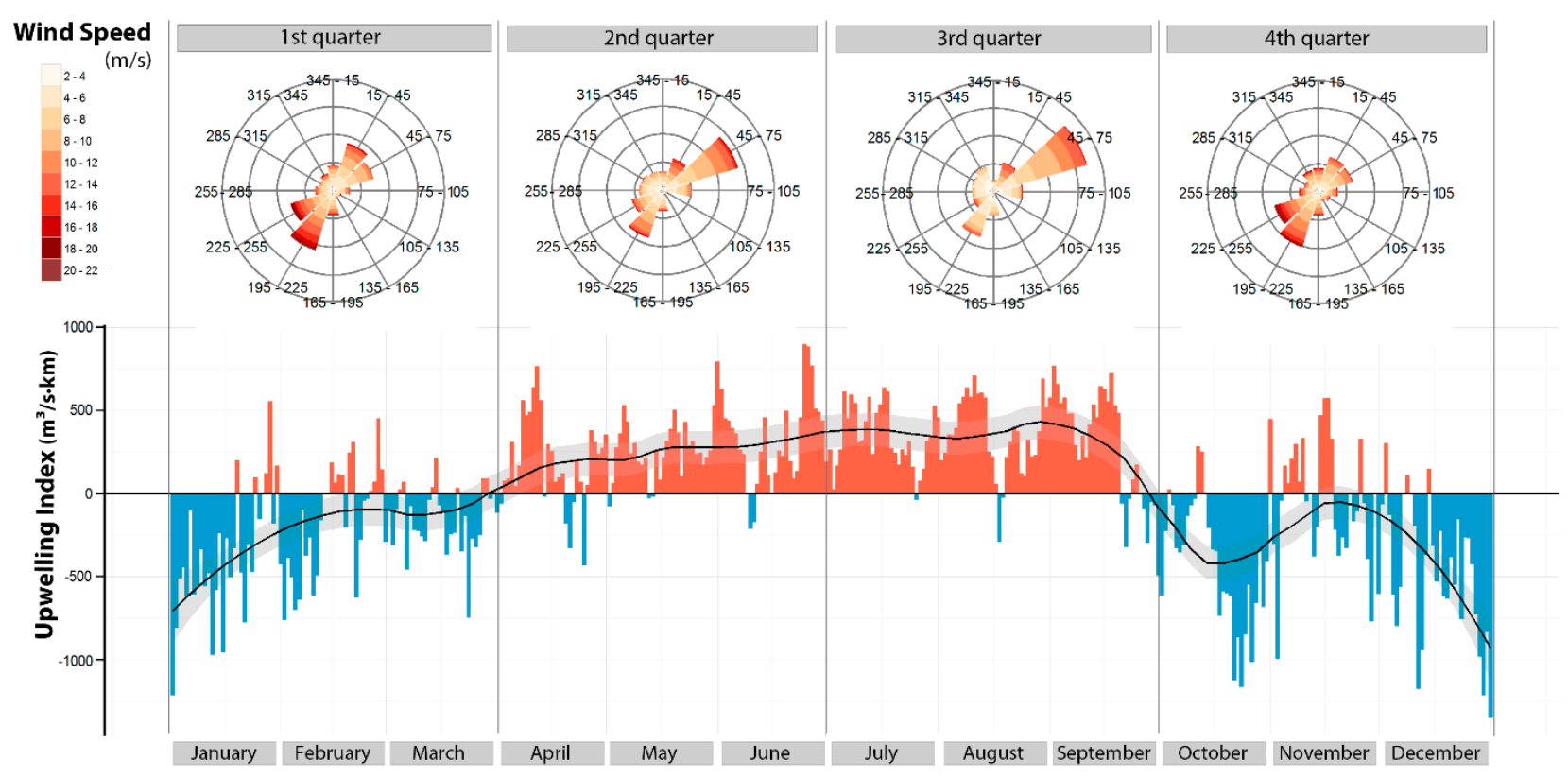

Fig. 2 Predominant winds calculated from the FMNOC model. Bearing (degrees) and intensity of predominant winds throughout the period of study split by seasons (quarters). Wind speed in coloured scale represented in metres per second (top figure). Mean Upwelling Index by day from the FMNOC model represented in metric tons per second per km of coast. Positive values in red and negative values in blue (bottom figure)

\subsection{Fishing effort and landings}

Three gears (or group of gears) were previously identified as primarily responsible for cetacean bycatches in the study area: gillnets, pair trawls and bottom trawls (López et al. 2002; Goetz et al. 2014b). For the current work, the fishing effort associated with these three gears was obtained from the "logbooks" which have been filled by fishermen with acceptable accuracy, although generally underestimated (Amandè et al. 2010), since 2003. In the logbooks the number of days that fishing boats go fishing is recorded. Therefore, number of days-at-sea (DAS) of gillnetters $\left(\mathrm{DAS}_{\text {Gill }}\right)$, pair trawlers $\left(\mathrm{DAS}_{\text {Pair }}\right)$ and bottom trawlers $\left(\mathrm{DAS}_{\text {Trawl }}\right)$ from 2003 to 2013 were tested as predictor variables.

The main prey species in the region for the three selected cetacean species are gadoids, mainly blue whiting (Micromesistius poutassou), in addition to clupeids, European hake (Merluccius merluccius) and carangids. These cetaceans are considered to be mainly opportunistic predators and feed on a wide variety of fish (e.g., Santos et al. 2013, 2014), although have preference for preys with a high energy content (Meynier et al. 2008; Spitz et al. 2010, 2012). In order to explore the relationship between the number of strandings and the availability of their main prey, landings of all fish (Land) and of blue whiting ( $\operatorname{Land}_{\mathrm{BW}}$ ) of the ports within 
the study area were downloaded from www.pescadegalicia.com and used as a proxy of relative fish abundance.

217 Table 1: Environmental variables used as predictors of the strandings patterns. Abbreviations as referenced in the text, whole name, periodicity used in the study, reference of the source and brief description.

\begin{tabular}{|c|c|c|c|c|}
\hline Abbreviation & Name & Periodicity & Source & Description \\
\hline Year & Year & Annual & Gregorian calendar & Year A.D. \\
\hline Month & Month & Monthly & Gregorian calendar & Ordinal position \\
\hline NAO & $\begin{array}{l}\text { North Atlantic } \\
\text { Oscillation }\end{array}$ & Monthly & $\begin{array}{l}\text { NOAA Climate Prediction } \\
\text { Center (NOAA - CPC) } \\
\text { http://www.cpc.noaa.gov/data/tel } \\
\text { edoc/nao.shtml }\end{array}$ & $\begin{array}{l}\text { Atmospheric sea level pressure } \\
\text { anomaly: difference in the } \\
\text { normalized sea level pressure } \\
\text { between Iceland and the Azores }\end{array}$ \\
\hline $\mathbf{N A O}_{W I N}$ & Winter NAO & Annual & Computed form NAO data & $\begin{array}{l}\text { Averaged over the NAO from } \\
\text { December to February }\end{array}$ \\
\hline EA & $\begin{array}{l}\text { East Atlantic } \\
\text { pattern }\end{array}$ & Monthly & $\begin{array}{l}\text { NOAA - CPC } \\
\text { http://www.cpc.noaa.gov/data/tel } \\
\underline{\text { edoc/ea.shtml }}\end{array}$ & $\begin{array}{l}\text { North-South dipole of anomaly } \\
\text { centres spanning the North } \\
\text { Atlantic from East to West }\end{array}$ \\
\hline SCA & $\begin{array}{l}\text { Scandinavian } \\
\text { pattern }\end{array}$ & Monthly & $\begin{array}{l}\text { NOAA - CPC } \\
\text { http://www.cpc.noaa.gov/data/tel } \\
\underline{\text { edoc/scand.shtml }}\end{array}$ & $\begin{array}{l}\text { Primary circulation centre over } \\
\text { Scandinavia, with weaker centres } \\
\text { of opposite sign over western } \\
\text { Europe and eastern Russia/ } \\
\text { western Mongolia }\end{array}$ \\
\hline UI & $\begin{array}{l}\text { Upwelling } \\
\text { index }\end{array}$ & Monthly & $\begin{array}{l}\text { IEO } \\
\text { http://www.indicedeafloramiento } \\
\underline{\text {.eo.es }}\end{array}$ & $\begin{array}{l}\text { Calculated using sea level } \\
\text { pressure data from the } \\
\text { atmospheric model WXMAP } \\
\text { (provided by FNMOC) }\end{array}$ \\
\hline UfMNOC & $\begin{array}{l}\text { FNMOC Wind } \\
\text { W-E } \\
\text { component }\end{array}$ & Monthly & $\begin{array}{l}\text { NOAA - FNMOC } \\
\text { https://www.fnmoc.navy.mil/wx } \\
\underline{\text { map_cgi/index.html }}\end{array}$ & $\begin{array}{l}\text { W-E component obtained from } \\
\text { the atmospheric model WXMAP }\end{array}$ \\
\hline VFMnOC & $\begin{array}{l}\text { FNMOC Wind } \\
\text { N-S component }\end{array}$ & Monthly & $\begin{array}{l}\text { NOAA - FNMOC } \\
\text { https://www.fnmoc.navy.mil/wx } \\
\underline{\text { map_cgi/index.html }}\end{array}$ & $\begin{array}{l}\text { N-S component obtained from } \\
\text { the atmospheric model WXMAP }\end{array}$ \\
\hline SW FMNOC & $\begin{array}{l}\text { FNMOC days } \\
\text { with southern } \\
\text { winds }\end{array}$ & Monthly & Computed from $\mathrm{V}_{\mathrm{FMNOC}}$ & $\begin{array}{l}\text { Number of days per month with } \\
\text { southern winds higher than } 10 \\
\mathrm{~m} \cdot \mathrm{s}^{-1} \text { (from FNMOC) }\end{array}$ \\
\hline UBUOY & $\begin{array}{l}\text { Buoy wind W- } \\
\text { E component }\end{array}$ & Monthly & $\begin{array}{l}\text { IEO } \\
\text { http://www.indicedeafloramiento } \\
\underline{\text { ieo.es }}\end{array}$ & $\begin{array}{l}\text { W-E component obtained from } \\
\text { the Sillero buoy }\end{array}$ \\
\hline VBUOY & $\begin{array}{l}\text { Buoy wind N-S } \\
\text { component }\end{array}$ & Monthly & $\begin{array}{l}\text { IEO } \\
\text { http://www.indicedeafloramiento } \\
\underline{\text { ieo.es }}\end{array}$ & $\begin{array}{l}\text { N-S component obtained from } \\
\text { the Silleiro buoy }\end{array}$ \\
\hline SW BUOY & $\begin{array}{l}\text { Buoy days with } \\
\text { southern winds }\end{array}$ & Monthly & $\overline{\text { Computed from } V_{\text {BUOY }}}$ & $\begin{array}{l}\text { Number of days per month with } \\
\text { southern winds higher than } 5 \\
\mathrm{~m} \cdot \mathrm{s}^{-1} \text { from the Silleiro buoy }\end{array}$ \\
\hline DAS $_{\text {Gill }}$ & $\begin{array}{l}\text { Gillnetters } \\
\text { days-at-sea }\end{array}$ & Monthly & Electronic logbooks & Gillnetters days-at-sea \\
\hline DASPair & $\begin{array}{l}\text { Pair trawlers } \\
\text { days-at-sea }\end{array}$ & Monthly & Electronic logbooks & Pair trawlers days-at-sea \\
\hline DAS $\mathbf{S}_{\text {Trawl }}$ & $\begin{array}{l}\text { Trawlers days- } \\
\text { at-sea }\end{array}$ & Monthly & Electronic logbooks & Trawlers days-at-sea \\
\hline Land & $\begin{array}{l}\text { Total fish } \\
\text { landings }\end{array}$ & Monthly & $\begin{array}{l}\text { Xunta de Galicia } \\
\text { http://www.pescadegalicia.com }\end{array}$ & $\begin{array}{l}\text { Total fish landings in fish } \\
\text { markets placed on the west coast } \\
\text { of Galicia }\end{array}$ \\
\hline
\end{tabular}




\begin{tabular}{|c|c|c|c|c|}
\hline Land ${ }_{\text {BW }}$ & $\begin{array}{l}\text { Blue whiting } \\
\text { landings }\end{array}$ & Monthly & $\begin{array}{l}\text { Xunta de Galicia } \\
\text { http://www.pescadegalicia.com }\end{array}$ & $\begin{array}{l}\text { Blue whiting landings in fish } \\
\text { markets placed on the west coast } \\
\text { of Galicia }\end{array}$ \\
\hline
\end{tabular}

\subsection{Data analysis}

All data-series of predictor variables were explored for outliers, normality, homogeneity of variances, colinearity, etc., following the protocol proposed by Zuur et al. (2010). Generalised Additive Models (GAMs) were then used to explore the spatial and temporal patterns in the data. Based on the different oceanographic characteristics of the northern and western coastline as outlined above, and preliminary results of the models, the two coasts were analysed separately by dividing the study region at the $43^{\circ}$ parallel into northern and western coasts. However, due to the low number of strandings recorded along the northern coast, further analysis for this area was not possible and, therefore, GAMs were fitted to explain the variability in strandings in terms of meteorological, oceanographic, landings and fishing effort variables (see Table 1) only for the western coastline (see Fig. 3 with a flow chart of the analytical processes).

Negative binomial GAMs with a log link were selected as they produced the best values of overdispersion among all tested combinations of models. A forward selection procedure was followed, including those explanatory variables that had a significant effect in explaining the seasonal and inter-annual variation in strandings. Final models were selected based on the Akaike Information Criterion (AIC), amount of deviance explained, R-squared and significance of covariates and smoothers. Knots of the smoother functions were automatically selected by cross-validation (except for the variable Month) since no overfitting was apparent in any case and there was no a priori reason to limit smoother shapes for the effects of temporal and spatial predictors.

Oceanographic and climatic variables usually show an annual cycle and are autocorrelated. Cyclical patterns in some variables revealed by spectral analysis were mainly annual (e.g., UI, U, and V) or too long (e.g., NAO, EA) to explain the patterns in our data-series. The annual cycle was taken into account in GAMs by including a smooth function for the seasonal term (Month) with a cyclic cubic spline, since there should not be a discontinuity between January and December, and the knots dimensions set to 12 , the maximum possible. When the cyclical pattern varied significantly between years, a 2-dimensional tensor smoother was included for Year and Month together, with a cyclic cubic spline for Month as before. Due to the correlation between some pairs of variables, they were not included together in the same model but different combinations were tested and compared.

Autocorrelation (AC) in response variables could be explained by the $\mathrm{AC}$ in the explanatory variables. However, when AC persisted in model residuals, Generalised Additive Mixed Models (GAMMs) were used 
to allow the inclusion of an annual correlation between samples by nesting an Autoregressive Moving Average model (ARMA) within each Year (applying a first-order autocorrelation in all models). Predictions of the models were plotted and their goodness of fit and quality of the prediction checked. Confidence intervals (CI) of final models were calculated assuming a normal distribution of their residuals.

To study the presence of trends or long-term change in the time-series, we created a model for each cetacean species with two smoothers describing within-year and between-year temporal variations. For the within-year or seasonal time variable we used the variable Month with a cycle cubic spline with 12 dimensions as in previous models. For the between-year or long-term trend, a new variable was created with the date of the observations represented numerically (Trend). GAMMs were fitted with these two smoothers and the annual correlation included with a first-order ARMA process using Year as correlated variable. Two models were fitted for each species, one with a cubic spline smoother in the Trend variable fitting a polynomial model and the other forcing a linear fit of this same variable to test if there was any long-term significant linear trend. Subsequently, the most significant variables identified in the GAMs described above were also included as covariates in these models together with Month and Trend variables (but not the Year variable in those cases when it had been considered significant, because of its correlation with the Trend variable). These models were also fitted both with smoothed and linear fit of the Trend variable. This modelling approach would account for the variability explained not only by the Trend but by other variables (e.g., V, SW and $\mathrm{NAO}_{\mathrm{WIN}}$ ) thus revealing any long-term change explained by variables not taken into account, which eventually, could be related to the abundance or distribution of cetaceans off the coast. The shape and significance of the fitted splines of the Trend variables were used to assess the existence of trends and patterns. In order to derive a 95\% CI for the fitted spline of the Trend variable, posterior simulations were also generated calculating a linear predictor matrix for the observations and multiplying it by 1000 samples randomly generated for each regression coefficient of the Trend variable assuming a multivariate normal distribution with the coefficients and their variance-covariance matrix.

A summary of the analysis performed is shown in Fig. 3. All models, analysis and data exploration were performed using R software, version 3.3.2 (R Core Team 2016). GAMs and GAMMs were fitted using the $m g c v$ library, version 1.8.0 (Wood 2011) 


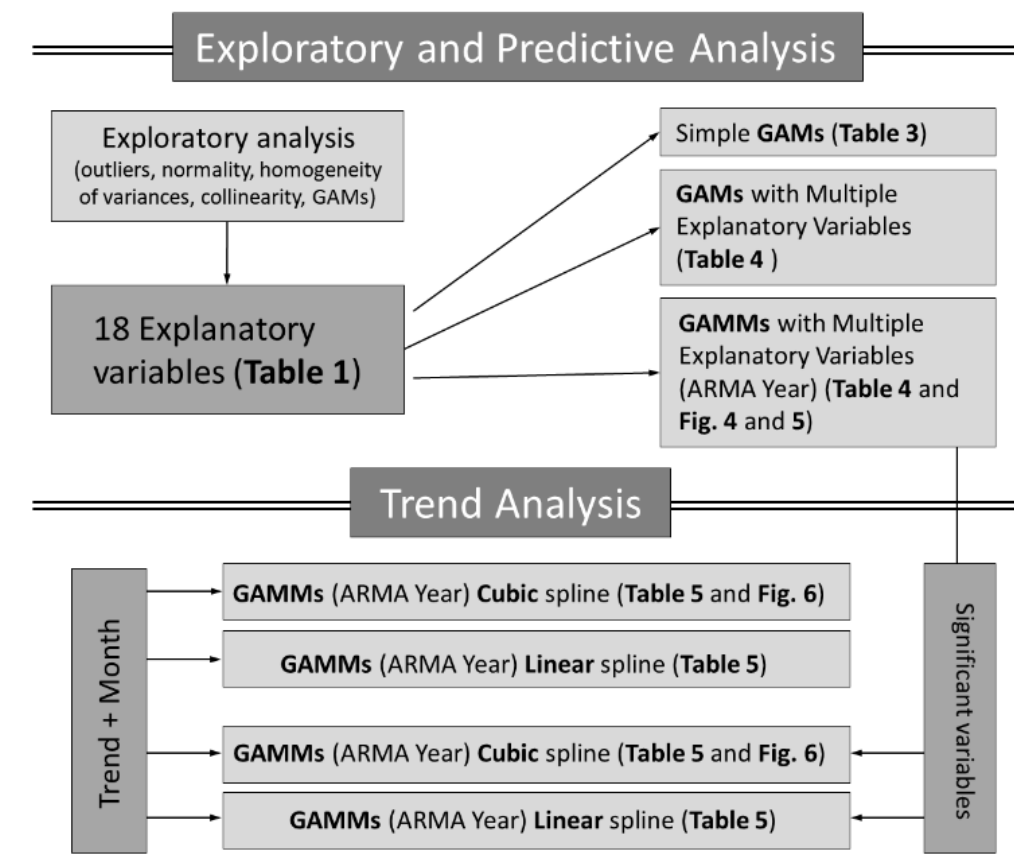

Fig. 3 Summary and flow chart of the analysis performed: Analytical processes (light grey), variables (grey), title of processes (dark grey).

\section{Results}

\subsection{Strandings data-series}

From 2000 to 2013, a total of 3249 cetaceans were recorded stranded or floating close to the Galician coast. Among these animals, 2035 (62.63\%) were identified as individuals of one of the three selected species, of which 1964 (83\%) were DDE, 200 (10\%) TTR and 141 (7\%) PPH. Around 3\% of these animals were found floating rather than stranded (44 DDE, 13 TTR and 4 PPH) and, therefore, were removed from the analysis. Almost 75\% (1374) of strandings took place on the western coast. Of all cetaceans found stranded, around $93 \%$ had a condition state $<5$ on the Kuiken \& Hartmann (1991) scale and were therefore used for the subsequent analysis. The most frequent condition state in carcases found in Galicia is 4 , with more than $50 \%$ of carcases, followed by state 3 with almost $30 \%$. These proportions are similar for the three species (Table 2).

Table 2: Stranded and floating dolphins from 2000 to 2013 along the North and West coasts of Galicia. The main figure in each case is the total number of animals in condition states 1 to 4 (following Kuiken and Hartmann 1991). Numbers of badly decomposed stranded animals (condition state 5) are given in parentheses. The total row represents the stranded and floating animals in all conditions. Cetacean species in columns: common dolphin (DDE), bottlenose dolphin (TTR) and harbour porpoise (PPH).

\begin{tabular}{ccccc} 
& DDE & TTR & PPH & Total \\
\hline Stranded & $1545(105)$ & $171(16)$ & $126(11)$ & $1842(132)$
\end{tabular}




\begin{tabular}{lrlrlrlrl}
\multicolumn{1}{r}{ North } & 379 & $(25)$ & 53 & $(7)$ & 36 & $(4)$ & 468 & $(36)$ \\
West & 1166 & $(80)$ & 118 & $(9)$ & 90 & $(7)$ & 1374 & $(96)$ \\
Floating & 44 & $(0)$ & 13 & $(0)$ & 4 & $(0)$ & 61 & $(0)$ \\
Total & 1589 & $(105)$ & 184 & $(16)$ & 130 & $(11)$ & 1903 & $(132)$ \\
\hline
\end{tabular}

The month-to-month pattern of strandings was generally similar every year, with a higher number of strandings in winter and a lower number in summer. The monthly mean through the time series is represented for all cetaceans aggregated in Fig. 1, as well as the total yearly number of strandings. The month-to-month pattern has remained fairly constant over the years as shown by the small standard error. The annual total number of strandings varied from year to year, although there was no clear trend over this time-scale.

\subsection{Stranding models}

\subsubsection{Simple GAMs}

Results of separate GAMs for each predictor variable showed slight differences between species (Table 3). Eleven of the eighteen explanatory variables considered (plus the interaction Year:Month) had a significant effect on the strandings pattern of DDE. The interaction Year:Month stood out with $\mathrm{p}<0.001$ and with $40.01 \%$ of the deviance explained, while Month, $\mathrm{V}_{\mathrm{FMNOC}}, \mathrm{SW}_{\mathrm{FMNOC}}, \mathrm{V}_{\mathrm{BUOY}}$ and UI explained 25.92\%, $11.07 \%, 9.95 \%, 9.64 \%$ and $9.15 \%$ of the deviance, respectively. For TTR fewer variables presented a significant effect on the strandings pattern. Significance was lower than 0.01 only in $\mathrm{V}_{\mathrm{BUOY}}, \mathrm{V}_{\mathrm{FMNOC}}$ and UI, with deviance explained of $6.71 \%, 4.89 \%$ and $4.33 \%$ respectively. However, three variables (Year, interaction Year:Month and $\left.\mathrm{NAO}_{\mathrm{WIN}}\right)$ were less significant $(0.01<\mathrm{p}<0.05)$ or marginally non-significant $(0.05<\mathrm{p}<0.1)$ but had a considerably higher deviance explained $(15.62 \%, 10.22 \%$ and $9.18 \%$, respectively). Relationships between the explanatory variables and PPH strandings were less significant, probably due to the smaller sample size. Month had a significant effect on strandings ( $\mathrm{p}<0.001)$ with a deviance explained of $11.60 \%$. The second most significant variable was $\mathrm{SW}_{\mathrm{FMNOC}}(\mathrm{p}<0.01$ and deviance explained of $8.98 \%$. Three marginally nonsignificant variables $\left(0.05<\mathrm{p}<0.1\right.$; interaction Year:Month and $\left.\mathrm{DAS}_{\text {Gill }}\right)$ showed a high deviance explained (18.44\% and $13.38 \%$ ) but others such as $\mathrm{V}_{\mathrm{FMNOC}}$, Land $\mathrm{BW}_{\mathrm{BW}}$ and UI explained a smaller percentage of deviance $(3.18 \%, 3.86 \%$ and $2.96 \%$, respectively).

Table 3: Simple GAMs for each predictor variable. The Fit column represents when the best fit was linear (L1) or a polynomial model of two (S2), three (S3), four (S4) degrees and so on. Deviance explained (Dev. Exp.) and p-value (pValue) is given for all models. Abbreviations of variables in rows as referenced in the text (see Table 1) and cetacean species in columns: common dolphin (DDE), bottlenose dolphin (TTR) and harbour porpoise (PPH).

DDE TTR PPH

\begin{tabular}{lcccccccccccc} 
& Fit & Dev.exp & pValue & sig. & Fit & Dev.exp & pValue & sig. & Fit & Dev.exp & pValue & sig. \\
\hline Year & L1 & 0.29 & 0.461 & & S4 & 9.18 & 0.021 & $*$ & S2 & 3.35 & 0.211 & \\
Month & S3 & $2 ., 92$ & $<0.001$ & $* * *$ & S2 & 5.71 & 0.015 & $*$ & S3 & 116 & 0.001 & $* * *$
\end{tabular}




\begin{tabular}{|c|c|c|c|c|c|c|c|c|c|c|c|c|}
\hline Year : Month & $\mathrm{S} 12$ & 40.01 & $<0.001$ & $* * *$ & S8 & 15.62 & 0.054 & & S9 & 18.44 & 0.033 & * \\
\hline NAO & $\mathrm{L} 1$ & 0.02 & 0.866 & & S3 & 4.43 & 0.239 & & $\mathrm{~L} 1$ & 0.47 & 0.401 & \\
\hline $\mathrm{NAO}_{\text {WIN }}$ & $\mathrm{S} 2$ & 5.03 & 0.014 & $*$ & S5 & 10.22 & 0.079 & & L1 & 0.02 & 0.878 & \\
\hline EA & $\mathrm{L} 1$ & 1.53 & 0.091 & . & L1 & 0.27 & 0.513 & & $\mathrm{~L} 1$ & 0.06 & 0.767 & \\
\hline SCA & $\mathrm{L} 1$ & 1.21 & 0.137 & & L1 & 0.78 & 0.269 & & L1 & 0.19 & 0.590 & \\
\hline UI & $\mathrm{S} 2$ & 9.15 & 0.001 & $* * *$ & L1 & 4.33 & 0.008 & $* *$ & $\mathrm{~L} 1$ & 2.96 & 0.029 & $*$ \\
\hline $\mathbf{U}_{\text {FMNOC }}$ & $\mathrm{L} 1$ & 3.04 & 0.016 & $*$ & L1 & 4.17 & 0.011 & $*$ & $\mathrm{~L} 1$ & 140 & 0.140 & \\
\hline VFMNOC & $\mathrm{S} 2$ & 11.07 & $<0.001$ & $* * *$ & L1 & 4.89 & 0.006 & $* *$ & $\mathrm{~L} 1$ & 3.18 & 0.025 & * \\
\hline $\mathbf{U}_{\text {BUOY }}$ & $\mathrm{L} 1$ & 3.97 & 0.034 & $*$ & S2 & 4.84 & 0.075 & . & L1 & 0.57 & 0.378 & \\
\hline VBuoy & $\mathrm{L} 1$ & 9.64 & $<0.001$ & $* * *$ & L1 & 6.71 & 0.002 & $* *$ & $\mathrm{~L} 1$ & 2.82 & 0.226 & \\
\hline SWFCNOC & $\mathrm{S} 2$ & 9.95 & $<0.001$ & $* * *$ & L1 & 3.42 & 0.017 & $*$ & $\mathrm{~S} 2$ & 8.98 & 0.003 & $* *$ \\
\hline SW BUOY & $\mathrm{L} 1$ & 0.38 & 0.826 & & L1 & 0.56 & 0.348 & & $\mathrm{~L} 1$ & 0.02 & 0.867 & \\
\hline $\mathbf{D A S}_{\text {Gill }}$ & $\mathrm{L} 1$ & 0.01 & 0.885 & & S2 & 4.65 & 0.274 & & S5 & 13.38 & 0.042 & * \\
\hline DASPair & $\mathrm{L} 1$ & 0.01 & 0.941 & & S3 & 7.5 & 0.128 & & $\mathrm{~L} 1$ & 0.05 & 0.806 & \\
\hline $\mathbf{D A S}_{\text {Trawl }}$ & $\mathrm{L} 1$ & 2.31 & 0.056 & . & L1 & 0.69 & 0.383 & & $\mathrm{~L} 1$ & 0.73 & 0.373 & \\
\hline Land & $\mathrm{L} 1$ & 2.91 & 0.015 & $*$ & L1 & 0.44 & 0.408 & & $\mathrm{~L} 1$ & 3.88 & 0.073 & $\cdot$ \\
\hline Land $_{B W}$ & $\mathrm{~L} 1$ & 0.51 & 0.339 & & L1 & 6.72 & 0.116 & & L1 & 3.86 & 0.015 & * \\
\hline
\end{tabular}

\subsubsection{GAMs with multiple explanatory variables}

After the selection of the individual variables with the highest explanatory power, models with different combinations of variables were explored for each cetacean species. The final DDE model included the interaction Year:Month, $\mathrm{NAO}_{\mathrm{WIN}}$ and $\mathrm{V}_{\mathrm{FMNOC}}$. All covariates in this final model were significant with a total deviance explained of 52\% (Table 4). For TTR, the final model included Year and $\mathrm{V}_{\text {BUOY }}$, with a deviance explained of only $14 \%$. The best model for PPH included Month and $\mathrm{SW}_{\mathrm{FMNOC}}$ with a deviance explained of 17\%. All covariates in these final models were significant. Autocorrelation (ACF) and partial autocorrelation 330 functions (PACF) applied for final models showed seasonal patterns in residuals, especially in the DDE model, 331 as well as high annual correlation between contiguous years.

Table 4: GAMs and GAMMs for each cetacean species. For each combination, predictor variable-cetacean species is 333 represented when the best fit was linear (L1) or a polynomial model of two (S2) or three (S3) degrees. AIC, Deviance explained (Dev. Exp.) and $\mathrm{R}$-squared $\left(\mathrm{R}^{2}\right)$ is given for all models. Abbreviations of variables in columns as referenced in the text (see Table 1) and cetacean species in rows: common dolphin (DDE), bottlenose dolphin (TTR) and harbour porpoise (PPH).

\section{Predictor variables}

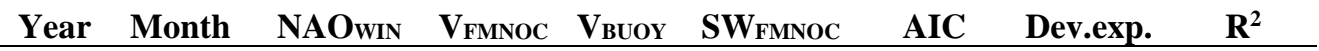




\begin{tabular}{|c|c|c|c|c|c|c|c|c|c|c|}
\hline \multirow{3}{*}{$\sum_{0}^{\infty}$} & DDE & \multicolumn{2}{|c|}{$\mathrm{S} 13 * * *$} & $\mathrm{~S} 3 * *$ & $\mathrm{~S} 2 *$ & - & - & 917 & $52 \%$ & 0.410 \\
\hline & TTR & $\mathrm{S} 3 *$ & - & - & - & L1 ** & - & 354 & $14 \%$ & 0.145 \\
\hline & PPH & - & $\mathrm{S} 2 * *$ & - & - & - & $\mathrm{S} 2 *$ & 319 & $17 \%$ & 0.124 \\
\hline \multirow{3}{*}{$\sum_{0}^{\infty}$} & DDE & \multicolumn{2}{|c|}{$\mathrm{S} 10 * * *$} & S2. & L1 $* * *$ & - & - & 441 & $57 \%$ & 0.366 \\
\hline & TTR & S3 * & - & - & - & L1 $* *$ & - & 543 & $26 \%$ & 0.137 \\
\hline & PPH & - & $\mathrm{S} 2 * *$ & - & - & - & $\mathrm{S} 2 *$ & 624 & $9 \%$ & 0.092 \\
\hline
\end{tabular}

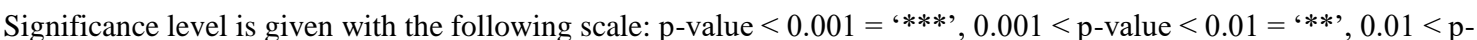
value $<0.05=$ '*', $0.05<$ p-value $<0.1=$ '?, and a hyphen $(-)$ representing when the variable is not used in the model.

\subsubsection{GAMMs}

GAMMs in which Year was added to the final GAMs as a correlated variable showed similar results

340 to the GAMs. Deviance explained is not comparable because the computational method is different. R-squared 341 values were similar although in general slightly lower for the GAMMs (Table 4). All selected covariates 342 remained significant in all models. Although some correlations could be still appreciated in the ACF and PACF 343 graphs, significant autocorrelation patterns disappeared and therefore, these models were considered more 344 appropriate. Illustrations of the effects of continuous explanatory variables can be seen in Fig. 4 . 


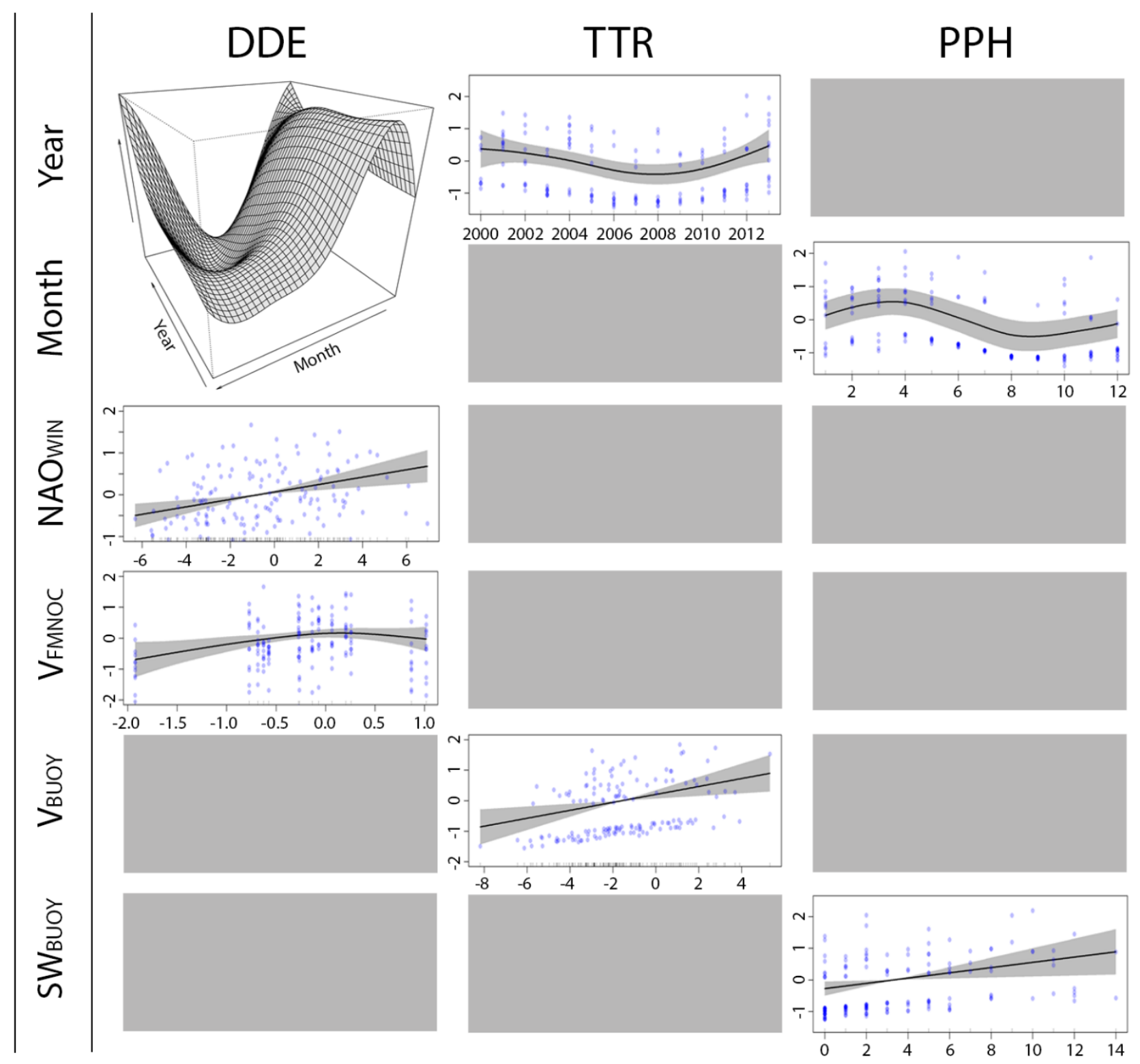

Fig. 4 Final GAMMs for $\log$ transformed number of individuals stranded: smoothers showing effects of explanatory variables retained in the final models. Rows represent the different variables: Year, Month, winter north Atlantic oscillation $\left(\mathrm{NAO}_{\mathrm{WIN}}\right)$, northerly component of the wind from the FMNOC model $\left(\mathrm{V}_{\mathrm{FMNOC}}\right)$ and from the Silleiro buoy $\left(\mathrm{V}_{\mathrm{BUOY}}\right)$, and number of days per month with strong favourable southwest winds from the FMNOC model ( $\mathrm{SW}_{\mathrm{FMNOC}}$ ). Columns represent the three cetacean species: common dolphin (DDE), bottlenose dolphin (TTR) and harbour porpoise (PPH). Grey squares represent not significant variables and dropped from the final models.

\subsubsection{Predictions}

Only the GAMM for DDE explained sufficient deviance (57\%) and had an acceptable quality of adjustment $\left(\mathrm{R}^{2}=0.366\right)$ as to be considered a fairly good predictive model. The results of the predictions performed using this model (for the time series period, not forward predictions) captured the annual and 
seasonal fluctuations along the time-series reasonably well; however, the model did not predict several instances of a very high number of strandings of DDE. The $95 \%$ of CI of the predictions of the model was also calculated by bootstrapping (Fig. 5).

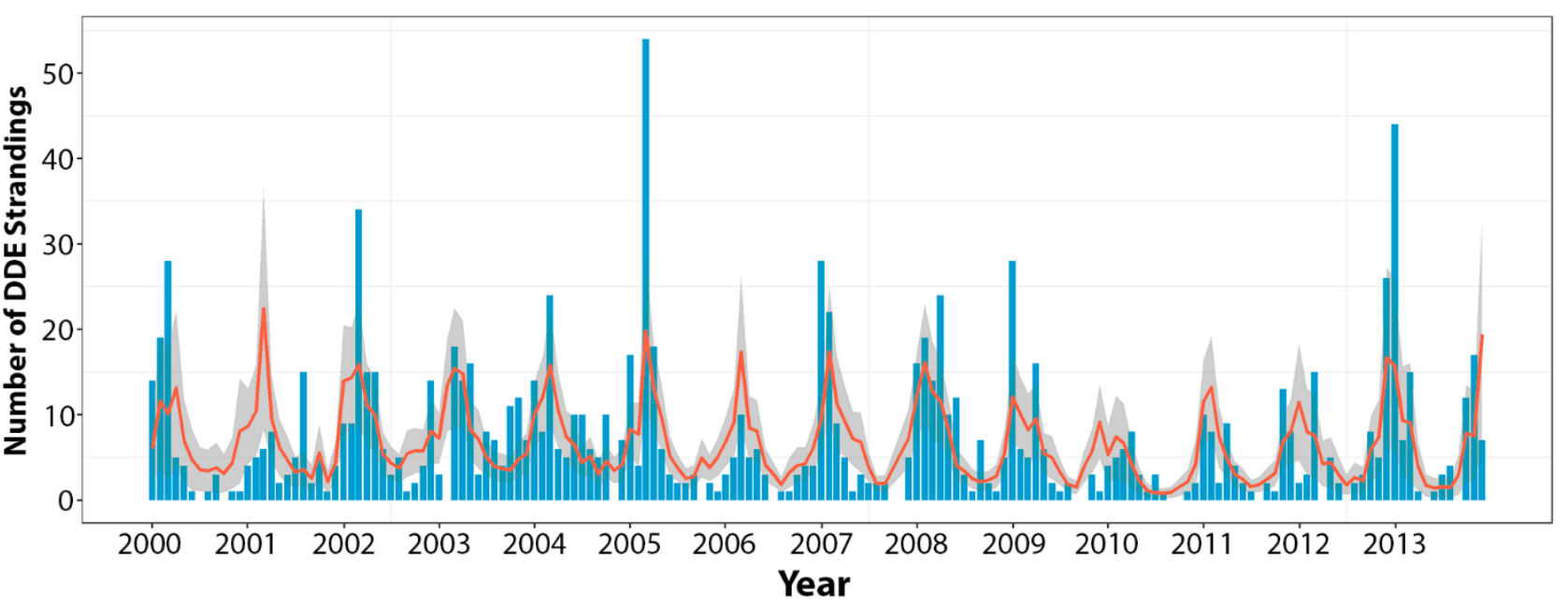

Fig. 5 The red line represents the estimations of the best common dolphin GAMM including Year:Month interaction, winter north Atlantic oscillation ( $\left.\mathrm{NAO}_{\mathrm{WIN}}\right)$ and northerly component of the wind from the FMNOC model $\left(\mathrm{V}_{\mathrm{FMNOC}}\right)$ as explanatory variables and Year as correlated variable, with 95\% CI (shaded grey). The blue bars are the observed number of common dolphin strandings per month.

\subsubsection{Trends}

The Trend variable was weakly significant for DDE and not significant for PPH, but Month showed high significance in both cases (Table 5). In TTR, monthly variation exhibited minor importance and the longterm temporal trend variable was more significant. Predicted number of strandings showed a similar pattern in TTR as in DDE but with a slightly more marked decline followed by a further increase in the first, with minima in 2011 and 2008, respectively. In the case of PPH, the stranding series showed a slight decline in the middle years of the series (Fig. 6). When Trend was linearized it was not significant in any of these species, indicating the absence of long-term linear trends in the numbers of strandings. When the selected significant variables were included in the models, the best fit for the Trend variable of the DDE became almost linear although nonsignificant (Table 5) and only small changes were seen in the TTR and PPH models. The patterns and variations in the fitted splines are shown in Fig. 6 with 95\% CI, both for the Trend variable treated as variations in the number of strandings and treated as a proxy of the abundance off the coast of the study area (i.e., model with only the Trend variable, and model with other covariates disentangling their effects). 
Table 5: GAMMs of annual and seasonal trends. For each combination predictor variable-cetacean species is represented when the best fit was a polynomial model of two (S2), three (S3) or four (S4) degrees. Deviance explained

Predictor variables

\begin{tabular}{|c|c|c|c|c|c|c|c|c|c|}
\hline & & \multirow[b]{2}{*}{ Trend } & \multirow[b]{2}{*}{ Dev.exp. } \\
\hline & & Year & Month & NAO & VFMNOC $_{\text {FNO }}$ & V $_{\text {BUOY }}$ & SWFMNOC $_{\text {FMN }}$ & & \\
\hline \multirow{3}{*}{ 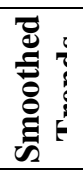 } & DDE & - & $\mathrm{S} 4 * * *$ & - & - & - & - & S4. & $46 \%$ \\
\hline & TTR & - & $\mathrm{S} 2$. & - & - & - & - & $\mathrm{S} 3 *$ & $21 \%$ \\
\hline & PPH & - & $\mathrm{S} 3 * *$ & - & - & - & - & $\mathrm{S} 2$ & $15 \%$ \\
\hline \multirow{3}{*}{ 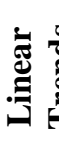 } & DDE & - & $\mathrm{S} 4 * * *$ & - & - & - & - & L1 & $38 \%$ \\
\hline & TTR & - & $\mathrm{S} 2$. & - & - & - & - & $\mathrm{L} 1$ & $7 \%$ \\
\hline & PPH & - & $\mathrm{S} 3 * *$ & - & - & - & - & L1 & $3 \%$ \\
\hline \multirow{3}{*}{ 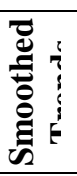 } & DDE & - & $\mathrm{S} 4 * * *$ & $\mathrm{~S} 2 *$ & $\mathrm{~L} 1 * * *$ & - & - & $\mathrm{S} 2$ & $44 \%$ \\
\hline & TTR & - & $\mathrm{L} 1$ & - & - & $\mathrm{L} 1 * *$ & - & $\mathrm{S} 3 *$ & $27 \%$ \\
\hline & PPH & - & $\mathrm{S} 3 * *$ & - & - & - & $\mathrm{L} 1 *$ & $\mathrm{~S} 2$ & $15 \%$ \\
\hline \multirow{3}{*}{ 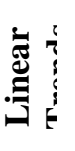 } & DDE & - & $\mathrm{S} 4 * * *$ & $\mathrm{~S} 2 *$ & $\mathrm{~L} 1 * * *$ & - & - & L1 & $44 \%$ \\
\hline & TTR & - & L1 & - & - & $\mathrm{L} 1 * *$ & - & L1 & $16 \%$ \\
\hline & PPH & - & S3 $*$ & - & - & - & $\mathrm{L} 1 *$ & L1 & $8 \%$ \\
\hline
\end{tabular}

Significance level is given with the following scale: $\mathrm{p}$-value $<0.001={ }^{*} * * *,, 0.001<\mathrm{p}$-value $<0.01=$ '**', $0.01<$ p-value $<0.05=$ '*', $0.05<$ p-value $<0.1=$ '?', and a hyphen (-) representing when the variable is not used in the model. 


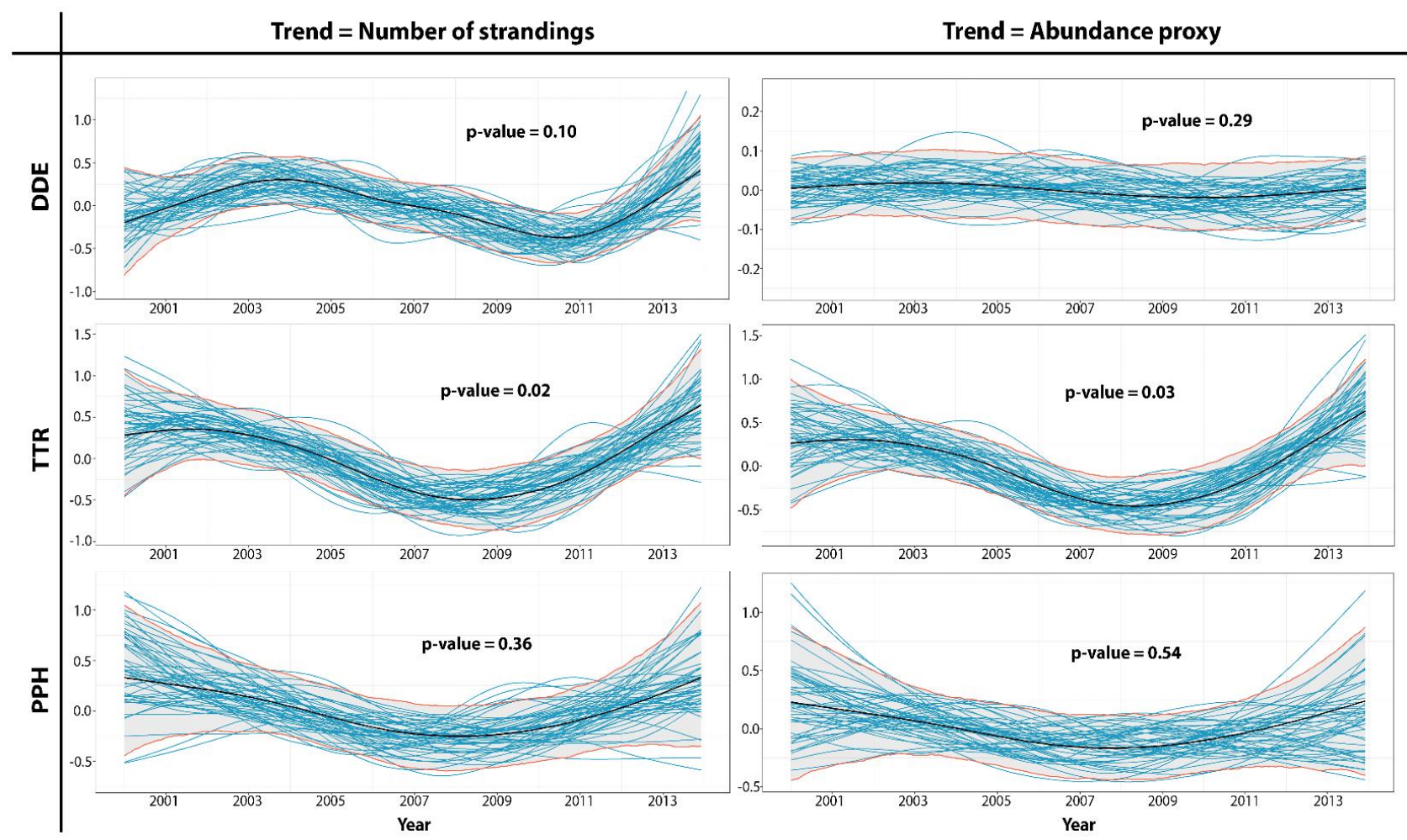

Fig. 6 GAMMs of annual and seasonal trends (dark lines) with 95\% CI (red lines) and 200 random runs of 1000 runs performed (blue lines). Models with Month, Trend and no other covariates (left column) and models with Month and Trend variables plus other explanatory covariates selected for the final models (right column). Cetacean species in rows: common dolphin (DDE), bottlenose dolphin (TTR) and harbour porpoise (PPH).

\section{Discussion}

Numerous authors have described stranding patterns in several regions around the world (e.g., López et al. 2002; Danil et al. 2010) and strandings have been considered a good indicator of the cetacean species present in a region, their relative abundance and their fidelity to an area (e.g., Pikesley et al. 2011; Pyenson 2011). Although in certain regions it has been considered that the oceanographic factors have little influence on the probability of stranding (Vishnyakova and Gol'din 2014), in many regions it has been shown that oceanographic conditions (Peltier et al. 2012, 2014), besides the variability in searching effort (López et al. 2002; Silva and Sequeira 2003; Maldini et al. 2005), can mask the relationship with annual and seasonal population abundances. In this study, in addition to oceanography, meteorology and climatic indices, fishing effort (i.e., days at sea) was included in the model as a potential proxy of fishing mortality (bycatch) - based on the assumption that cetacean bycatch rates depend on fishing effort and cetacean abundance (e.g., Read et al. 2006), since it may also substantially affect the number of strandings in regions where a high level of interactions between cetaceans and fisheries has been reported, as it is the case in Galicia (López et al. 2002; 
Silva and Sequeira 2003). Moreover, landings were also included as proxies of presence/abundance of prey species, as one would expect number of cetaceans to be higher (and thus also the number of strandings) in regions and seasons where the abundance of prey species is higher (Vishnyakova and Gol'din 2014). To avoid variability due to differential sampling effort (in the search for strandings) we have restricted the analysis to the last fourteen years of the time-series, when the searching effort can be considered to have been reasonably constant.

Results of our analysis in the southern region of Galicia (west coast) have demonstrated that, among the variables tested, those related with the wind strength and direction (i.e., V, SW) have the strongest influence on the variability observed in the number of strandings. The $\mathrm{V}$ component of the wind provides information about both the strength and N-S direction of the predominant winds (i.e., more positive values mean more southerly and stronger winds). These variables are highly correlated and, although from different sources, all demonstrate the existence of positive relationships between S-SW winds and the number of strandings in all cetacean species. The relationships between these indices and the strandings patterns seem coherent and agree, to some extent, with findings by López et al. (2002) for the same study region. The upwelling index (UI) showed significant relationships with number of strandings for the three cetacean species but, because of the correlation of UI with the wind variables, only the latter $\left(\mathrm{V}_{\mathrm{FMNOC}}, \mathrm{V}_{\mathrm{BUOY}}\right.$ and $\left.\mathrm{SW}_{\mathrm{FMNOC}}\right)$ were included in the final models because of the presence of a stronger relationship, as indicated by the higher significance of the effect in the model. As the southern coast of Galicia has a western orientation and is located in the northern hemisphere, constant winds from the north and northwest produce upwelling, displacing water away from the coast. These events, which predominate in the summer months, reduce the probability of stranding, moving the carcasses away from the coast. On the contrary, in the winter months, predominant southerly winds produce downwelling which, together with the prevailing winds, facilitate that carcasses reach the coast. In addition, during these winter months the number of days with strong winds, their intensity (related with storms) and the prevailing direction, make the probability of stranding greater. This information is partially captured by the wind variables and we observed a high relationship between them and the number of strandings.

Large-scale ocean climate indices, such as EA, SCA and annual NAO, did not show any clear relationships with stranding patterns for any of the cetacean species. For example, the NAO index, for which the positive phase is associated with higher pressures in the subtropical high pressure centre, causes the weather in western and southern Europe to be more stable. The opposite occurs during negative NAO years, when the high and low pressure centers are weakened, resulting in more frequent and intense winter storms crossing the Atlantic Ocean that, in turn, are related with strong western winds in our study area. Therefore, it would be reasonable to expect that negative NAO events will result in a higher number of strandings. No such relationship was detected in our analysis when using the monthly mean NAO. Similar relationships might occur with the EA and SCA; however, again, no evidence of a relationship was found. The lack of apparent 
relationship with these climate indices could be due to masking by some other more powerful process. Nevertheless, when a component of the NAO, the winter NAO (NAO ${ }_{\text {WIN }}$; i.e., the mean NAO of the winter months, December through March) was used as a predictor variable, it provided a good fit and the deviance explained was also satisfactory for all cetacean species, especially for DDE, for which NAO WIN $_{\text {was included }}$ in the final model since its effect on the number of strandings was significant. However, the effect was opposite to expected, with more strandings in positive phases than in negative. The significant effect on the number of DDE strandings could be explained not by the local effect that the NAO exerts on the probability of stranding but on the behaviour of the species. Although there is no evidence to confirm this hypothesis, the migratory patterns of the species could cause the common dolphin to move to quieter waters (or further away from the coast) during negative phases of NAO. This would make to decrease their abundance in the study area, which would be reflected in the number of strandings.

We might expect that bycatch would be related to the level of fishing effort as demonstrated in various studies (e.g., Northridge 1984, 1991; Read et al. 2006). However, when the fishing effort (DAS Gill, $_{\text {DAS }}$ Pair and $\mathrm{DAS}_{\text {Trawl }}$ ) and landings (Land and Land $_{\mathrm{BW}}$ ) were tested, no significant relationships were found with strandings of the three cetacean species. At first sight, our results would seem to contradict the available data, i.e. the high number of stranded cetaceans with evidence of having been bycaught. However, absence of a relationship between the fishing effort and the number of strandings may be due to the fact that annual fishing effort did not vary greatly during the study period (2000-14). In addition, data on trawling or soaking time are not readily available, forcing us to use the number of trips as a measure of effort. It should also be noted that logbooks are only available for boats larger than $10 \mathrm{~m}$, effectively leaving out the information on the effort of the artisanal fleet, which is responsible for a large part of the gillnet effort in Galician waters. Gillnets are responsible for a substantial proportion of cetacean bycatches in Galicia (Goetz et al. 2014b). In addition, cetaceans can drift for a long time before sinking. Decomposition experiments on mammal carcases submerged in salt water carried out by Anderson \& Hobischak (2004) demonstrated that buoyancy of carcases was still present 47 day after death and remains were recovered even 140 days after death. Thus, animals with condition state of 4 (i.e., advanced decomposition; Kuiken and Hartmann 1991), including 57\% of the recorded carcases of the present study, may correspond to a time after dead of 30 - 40 days (Anderson and Hobischak 2004), indicate that our samples could have drifted for a long time (and indeed over a long distance) prior to stranding. Peltier et al. (2012) registered a dolphin carcass which travelled more than $77 \mathrm{~km}$ in only 9 days and Martínez-Cedeira (2011) recorded another carcass that travelled more than $300 \mathrm{~km}$ with favourable weather conditions. Therefore, since southerly winds favour transport and stranding of carcases in our study region, many dolphin carcasses stranded in Galicia could have travelled from Portuguese waters. If this is the case and dolphins have been bycaught outside Galician waters, it would be necessary to include the activities of the Portuguese fleet in our analyses. This complicates the identification of a relationship between number of strandings and fishing 
effort, as can occur in places with a marked seasonal difference in abundance and distribution (e.g., Fruet et al. 2010). Furthermore, metiers targeting preferred prey probably have higher bycatch than those targeting other species (e.g., Spitz et al. 2013), although within metiers, bycatch may still be related to fishing effort. Therefore, effort aggregated by fishing gear as the used here, and not by specific metier, is likely not the best indicator to measure the probability of bycatch. However, at present, the metier-specific information is not available.

We used the total monthly amount of fish landed in all ports of the southern region of Galicia, regardless of the species or size of these fish, as an indication of food availability to cetaceans. Using just the length classes of fish susceptible to be eaten by dolphins was not possible with the available database. Although we would expect some relationship between fish abundance and fishery landings, evidently, landings may not always be a good index of fish abundance. For instance, targeted effort can be directed at certain size classes and fish species, the landings data do not include information on amounts of fish discarded and landings may be limited by quota restrictions in some species. Using the estimated annual abundance of the main target species, as Vishnyakova \& Gol'din (2014) did, might be more suitable. However, assessment of the blue whiting stock (one of the main prey species of the studied cetaceans) is not currently performed at the scale of our study area and abundance estimates for blue whiting were thus not available for our analysis.

In this study, factors such as the distance away from the coast when the animal died and the buoyancy of the carcass could not be considered. The cetaceans analysed in this study mainly inhabit the slope and shelf continental waters and as other studies have shown, cetacean carcasses can drift long distances (MartínezCedeira et al. 2011; e.g., Peltier et al. 2012). In our analysis, we have implicitly assumed that any cetacean dying within the continental shelf might reach the coast and strand. In practice, the likelihood of stranding probably depends more on the prevailing oceanographic conditions than on the distance to the coast; a cetacean dying near the coast would not reach the coast if the conditions were unfavourable. Regarding the buoyancy, it depends on body size as well as on body composition (Peltier et al. 2012, 2016), which may explain why very small animals seem to be under-represented in strandings data (Stolen and Barlow 2003). In order to interpret the strandings data, ideally we need to know about the body size distribution of the living population.

Because the explanatory variables used were not sufficient to adequately explain the annual and seasonal variability, we included Month and Year as additional predictor variables. Although these variables in themselves cannot explain numbers of strandings, they indirectly carry biological or physical information that is not available in other explanatory variables. The abundance of dolphins in a particular year is presumably related to their abundance in the previous year due to their longevity and thus, we assumed that a certain degree of annual autocorrelation is to be expected. Using GAMMs to take this autocorrelation into account, the resulting models showed generally similar levels of significance for explanatory variables and 
indicators of the quality of the model fit (AIC, deviance explained and $\mathrm{R}^{2}$ ) improved in some cases, although not in all of them. For DDE, our model explained 57\% of deviance and captures the annual and seasonal fluctuations along the time-series reasonably well. The model did not predict several instances of a very high number of strandings. These peaks of strandings may reflect unusual mortality events or ocean climate events (such as storms) not captured by the explanatory variables in the model.

The study of the long-term patterns in the number of strandings revealed year-to-year fluctuations (only significant in TTR and marginally significant in DDE), but no linear trends in the number of strandings for any of the species analysed. When other explanatory variables (mainly the annual variations of the $\mathrm{NAO}_{\text {WIN }}$ ) were included in the model to try to test if these changes in the number of strandings could be related to changes in their abundance, the slightly significant variations observed in the DDE model disappeared, becoming linear and non-significant. This result would seem to indicate a relatively stable abundance of DDE off the Galician coasts in the period of study.

When the effect of the Trend variable was linearized, it was not significant for any of the studied species. If we assume that the Trend variable represents abundance, we could conclude that there is no linear trend of increase or decrease in their long term abundance. However, examination of Fig. 6 suggests that the bottlenose dolphin population in the area may have suffered a slight decrease, shortly after half of our time series, and subsequent increase of its population. Depending on the time period over which abundance were evaluated, conclusions could clearly differ but with the whole data set available there is no evidence of an overall decline or increase.

To be able to use strandings as indicators to support decisions on cetacean management and conservation, it is important to take into consideration the factors that influence them (Peltier et al. 2014, 2016). As we have shown, the effects of the multiple explanatory variables which interact among themselves are sometimes not easy to interpret, particularly when the number of observations are limited, such as with TTR and PPH strandings. The models presented provide an example of how combining strandings, environmental and other fishing-related variables could be used to explain the abundance trends and their variations to generate an operational indicator of abundance trends. However, factors and events leading strandings are evidently complex and it is important to obtain better predictors, especially of prey abundance and fishery bycatch mortality of cetaceans. Examination of the relative frequency of different causes of death can provide an insight into whether increased mortality rate is a component in an increased number of strandings. If these frequencies varied throughout our study period, they could mask the relationship between strandings and the abundance of cetaceans. Indices of fish abundance and information on fish spatial distribution, derived from fisheries assessment surveys, can be related to cetacean diet and thus offer insights into changes in cetacean distribution. Recently, models based on ocean currents have shown how carcase drift may be accounted for 
538 (Peltier et al., 2012). These models can provide extra information about processes not captured by the variables 539 used in this study. Clearly, there are additional steps that can be performed to improve the predictive capacity 540 of our models. However, many of them are complex or not fully feasible, so we consider that the approach we 541 have used offers an important step to better understand the stranding process and its possible relationship with 542 the abundance of these species

544 Conflict of Interest: The authors declare that they have no conflict of interest. 


\section{References}

Amandè MJ, Ariz J, Chassot E, et al (2010) Bycatch of the European purse seine tuna fishery in the Atlantic Ocean for the 2003-2007 period. Aquat Living Resour 23:353-362. doi: 10.1051/alr/2011003

Anderson GS, Hobischak NR (2004) Decomposition of carrion in the marine environment in British Columbia, Canada. Int J Legal Med 118:206-209. doi: 10.1007/s00414-004-0447-2

Caughlan L, Oakley KL (2001) Cost considerations for long-term ecological monitoring. Ecol Indic 1:123134. doi: 10.1016/S1470-160X(01)00015-2

CODA Final Report (2009) Cetacean Offshore Distribution and Abundance in the European Atlantic (CODA) (No. WC04016). Sea Mammal Research Unit.

Council Directive 92/43/EEC of 21 May 1992 on the conservation of natural habitats and of wild fauna and flora. OJ L 206/7.

Danil K, Chivers SJ, Henshaw MD, et al (2010) Cetacean strandings in San Diego Country, California, USA: 1851-2008. J Cetacean Res Manag 11:163-184.

Directive 2008/56/EC of the European Parliament and of the Council of 17 June 2008 establishing a framework for community action in the field of marine environmental policy (Marine Strategy Framework Directive). OJ L 164/19.

Elzinga C, Salzer D, Willoughby JW, Gibbs JP (2001) Monitoring Plant and Animal Populations. Blackwell Science, United States of America

Evans K, Thresher R, Warneke RMM, et al (2005) Periodic variability in cetacean strandings: links to largescale climate events. Biol Lett 1:147-150. doi: 10.1098/rsbl.2005.0313

Fernández-Contreras MM, Cardona L, Lockyer CH, Aguilar A (2010) Incidental bycatch of short-beaked common dolphins (Delphinus delphis) by pairtrawlers off northwestern Spain. ICES J Mar Sci 67:1732-1738. doi: 10.1093/icesjms/fsq077

Fernández R, García-Tiscar S, Santos MB, et al (2011) Stable isotope analysis in two sympatric populations of bottlenose dolphins Tursiops truncatus: evidence of resource partitioning? Mar Biol 158:1043-1055.

Fontaine MC, Tolley KA, Michaux JR, et al (2010) Genetic and historic evidence for climate-driven population fragmentation in a top cetacean predator: the harbour porpoises in European water. Procedings R Soc Biol Sci 277:2829-2837. doi: 10.1098/rspb.2010.0412 
Friedlaender AS, Halpin PN, Qian SS, et al (2006) Whale distribution in relation to prey abundance and oceanographic processes in shelf waters of the Western Antarctic Peninsula. Mar Ecol Prog Ser 317:297-310.

Fruet PF, Kinas PG, da Silva KG, et al (2010) Temporal trends in mortality and effects of by-catch on common bottlenose dolphins, Tursiops truncatus, in southern Brazil. J Mar Biol Assoc United Kingdom 92:1-12. doi: 10.1017/S0025315410001888

Goetz S, Read FL, Ferreira M, et al (2014a) Cetacean occurrence, habitat preferences and potential for cetacean-fishery interactions in Iberian Atlantic waters: results from cooperative research involving local stakeholders. Aquat Conserv Mar Freshw Ecosyst 25:138-154. doi: 10.1002/aqc.2481

Goetz S, Read FL, Santos MB, et al (2014b) Cetacean-fishery interactions in Galicia (NW Spain): results and management implications of a face-to-face interview survey of local fishers. ICES J Mar Sci 71:604-617. doi: 10.1093/icesjms/fst149

González-Nuevo G, Gago J, Cabanas JM (2014) Upwelling index: a powerful tool for marine research in the NW Iberian upwelling system. J Oper Oceanogr 7:47-57. doi: 10.1080/1755876X.2014.11020152

Kuiken T (1994) Review of the criteria for the diagnosis of by-catch in cetaceans. In: Kuiken T (ed) Proceedings of the 2nd Annual Conference of the European Cetacean Society, ECS Newsle. Montpellier, France, 2 March 1994, pp 38-43

Kuiken T, Hartmann M (1991) Proceedings of the First ECS Workshop on Cetacean Pathology: dissection techniques and tissue sampling. In: Kuiken T, Hartmann MG (eds). European Cetacean Society, Leiden, the Netherlands, 13-14 September 1991, p 43

Leeney RH, Amies R, Broderick AC, et al (2008) Spatio-temporal analysis of cetacean strandings and bycatch in a UK fisheries hotspot. Biodivers Conserv 17:2323-2338.

López-Jamar E, Cal RM, González G, et al (1992) Upwelling and Outwelling Effects on the Benthic Regime of the Continental-Shelf Off Galicia, Nw Spain. J Mar Res 50:465-488.

López A (2003) Estatus dos pequenos cetáceos da plataforma de Galicia. PhD Thesis, University of Santiago de Compostela, Spain.

López A, Pierce GJ, Santos MB, et al (2003) Fishery by-catches of marine mammals in Galician waters: results from on-board observations and an interview survey of fishermen. Biol Conserv 111:25-40. doi: http://dx.doi.org/10.1016/S0006-3207(02)00244-6 
López A, Santos MB, Pierce GJ, et al (2002) Trends in strandings and by-catch of marine mammals in northwest Spain during the 1990s. J Mar Biol Assoc United Kingdom 82:513-521.

Maldini D, Mazzuca L, Atkinson S (2005) Odontocete Stranding Patterns in the Main Hawaiian Islands (1937 - 2002): How Do They Compare with Live Animal Surveys? Pacific Sci 59:55-67.

Martínez-Cedeira J, Morales X, Garcia JA, et al (2011) How many strand? Offshore marking and coastal recapture of cetacean carcasses. In: Proceedings of the 25th Annual Conference of the European Cetacean Society. Cádiz, Spain, 21-23 May 2011,

Méndez-Fernandez P, Webster L, Chouvelon T, et al (2014) An assessment of contaminant concentrations in toothed whale species of the NW Iberian Peninsula: Part I. Persistent organic pollutants. Sci Total Environ 484:196-205. doi: 10.1016/j.scitotenv.2014.02.045

Meynier L, Pusineri C, Spitz J, et al (2008) Intraspecific dietary variation in the short-beaked common dolphin textit Delphinus delphis in the Bay of Biscay: importance of fat fish. Mar Ecol Prog Ser 354:277-287. doi: 10.3354/meps07246

Murphy S, Pinn EH, Jepson PD (2013) The Short-Beaked Common Dolphin (Delphinus delphis) in the North-East Atlantic: Distribution, Ecology, Management and Conservation Status. Oceanogr Mar Biol An Annu Rev 51:193-280.

Northridge SP (1984) World review of interactions between marine mammals and fisheries. FAO Fisheries Technical Paper. No. 251, Rome

Northridge SP (1991) An updated world review of interactions between marine mammals and fisheries. FAO Fisheries Technical Paper. No. 251, Rome

Peltier H, Authier M, Deaville R, et al (2016) Small cetacean bycatch as estimated from stranding schemes: The common dolphin case in the northeast Atlantic. Environ Sci Policy 63:7-18. doi: 10.1016/j.envsci.2016.05.004

Peltier H, Dabin W, Daniel P, et al (2012) The significance of stranding data as indicators of cetacean populations at sea: Modelling the drift of cetacean carcasses. Ecol Indic 18:278-290.

Peltier H, Jepson PD, Dabin W, et al (2014) The contribution of stranding data to monitoring and conservation strategies for cetaceans: Developing spatially explicit mortality indicators for common dolphins (Delphinus delphis) in the eastern North-Atlantic. Ecol Indic 39:203-214. doi: 10.1016/j.ecolind.2013.12.019 
Pierce GJ, Caldas M, Cedeira J, et al (2010) Trends in cetacean sigths along the Galician coast, north-west Spain, 2003-2007, and inferences about cetacean habitat preferences. J Mar Biol Assoc United Kingdom 90:1547-1560.

Pierce GJ, Santos MB, Murphy S, et al (2008) Bioaccumulation of persistent organic pollutants in female common dolphins (Delphinus delphis) and harbour porpoises (Phocoena phocoena) from western European seas: Geographical trends, causal factors and effects on reproduction and mortalit. Environ Pollut 153:401-415. doi: 10.1016/j.envpol.2007.08.019

Pikesley SK, Witt MJ, Hardy T, et al (2011) Cetacean sightings and strandings: evidence for spatial and temporal trends? J Mar Biol Assoc United Kingdom 1-12. doi: 10.1017/S0025315411001470

Pyenson ND (2011) The high fidelity of the cetacean stranding record: insights into measuring diversity by integrating taphonomy and macroecology. Proc R Soc B Biol Sci 278:3608-3616. doi: 10.1098/rspb.2011.0441

R Core Team (2016) R: A language and environment for statistical computing.

Read AJ, Drinker P, Northridge S (2006) Bycatch of marine mammals in U.S. and global fisheries. Conserv Biol 20:163-169. doi: 10.1111/j.1523-1739.2006.00338.x

Santos MB, German I, Correia D, et al (2013) Long-term variation in common dolphin diet in relation to prey abundance. Mar Ecol Prog Ser 481:249-268. doi: 10.3354/meps10233

Santos MB, Saavedra C, Pierce GJ (2014) Quantifying the predation on sardine and hake by cetaceans in the Atlantic waters of the Iberian peninsula. Deep Sea Res Part II Top Stud Oceanogr 106:232-244. doi: http://dx.doi.org/10.1016/j.dsr2.2013.09.040

SCANS-II (2006) Design-based abundance estimates from SCANS-II. In: Burt M, Borchers D, Paxton C (eds) Small Cetaceans in the European Atlantic and North Sea. Final Report to the European Commission under project LIFE04NAT/GB/000245, St. Andrews, p 31

Siebert U, Gilles A, Lucke K, et al (2006) A decade of harbour porpoise occurrence in German watersAnalyses of aerial surveys, incidental sightings and strandings. J Sea Res 56:65-80. doi: 10.1016/j.seares.2006.01.003

Silva M a., Sequeira M (2003) Patterns in the mortality of common dolphins (Delphinus delphis) on the Portuguese coast, using stranding records, 1975-1998. Aquat Mamm 29:88-98. doi: $10.1578 / 016754203101023924$ 
Spitz J, Chouvelon T, Cardinaud M, et al (2013) Prey preferences of adult sea bass Dicentrarchus labrax in the northeastern Atlantic: implications for bycatch of common dolphin Delphinus delphis. ICES J Mar Sci 70:452-461.

Spitz J, Mourocq E, Leauté J-P, et al (2010) Prey selection by the common dolphin: Fulfilling high energy requirements with high quality food. J Exp Mar Bio Ecol 390:73-77.

Spitz J, Trites AW, Becquet V, et al (2012) Cost of living dictates what whales, dolphins and porpoises eat: the importance of prey quality on predator foraging strategies. PLoS One 7:e50096.

Spyrakos E, Santos-Diniz T, Martínez-Iglesias G, et al (2011) Spatiotemporal patterns of marine mammal distribution in coastal waters of Galicia, NW Spain. Hydrobiologia 670:87-109.

Stolen M, Barlow J (2003) A model life table for bottlenose dolphins (Tursiops truncatus) from the Indian River Lagoon System, Florida, USA. Mar mammal Sci 19:630-649. doi: 10.1111/j.17487692.2003.tb01121.x

Truchon M-H, L'Hérault V, Brêthes J-C, et al (2013) Marine Mammal Strandings and Environmental Changes: A 15-Year Study in the St. Lawrence Ecosystem. PLoS One 8:59311.

Vishnyakova K, Gol'din P (2014) Cetacean stranding rate correlates with fish stock dynamics: research of harbour porpoises in the Sea of Azov. Mar Biol 162:359-366. doi: 10.1007/s00227-014-2600-x

Wood SN (2011) Fast stable restricted maximum likelihood and marginal likelihood estimation of semiparametric generalized linear models. J R Stat Soc Ser B 73:3-36.

Wooster WS, Bakun A, McLain DR (1976) Seasonal upwelling cycle along eastern boundary of NorthAtlantic. J Mar Res 34:131-141.

Xunta de Galicia (2016) Pesca de Galicia. http://www.pescadegalicia.com/rexbuque.html. Accessed 25 Jun 2016

Zuur AF, Ieno EN, Elphick CS (2010) A protocol for data exploration to avoid common statistical problems. 685 